\title{
Avaliação de métodos, concentrações de inóculo e idade das plântulas para inoculação de Phytophthora palmivora em mamoeiro
}

\author{
Tacila Ribeiro Santos \& Edna Dora M.N. Luz \\ Comissão Executiva do Plano da Lavoura Cacaueira, Centro de Pesquisa do Cacau, Setor de Fitopatologia, 45600-970, \\ Ilhéus, BA, Brasil
}

Autor para correspondência: Edna Dora M.N. Luz, e-mail: ednadora@cepec.gov.br

\begin{abstract}
RESUMO
Foram realizados três experimentos em delineamento inteiramente casualizado com 10 repetições por tratamento para avaliar três métodos de inoculação de Phytophthora palmivora, cinco concentrações de inóculo e quatro idades de plântulas de mamoeiro, visando testar a resistência à podridão-do-pé. No experimento 1 foram testados: três genótipos - Golden, Kapoho Solo e Calimosa, aos 60 dias após a semeadura; três métodos de inoculação - deposição de $1 \mathrm{~mL}$ do inóculo no substrato encharcado (DSE), idem sem encharcamento (DSS) e imersão do sistema radicular em $200 \mathrm{~mL}$ de suspensão de zoósporos (ISR) e cinco concentrações de inóculo $5 \times 10^{3}, 10^{4}, 5 \times 10^{4}$, $10^{5}$ e $5 \times 10^{5}$ zoósporos $/ \mathrm{mL}$. No experimento 2, foram avaliados: dois genótipos - Golden e Kapoho Solo; dois métodos (DSE e DSS) e três concentrações $\left(1 \times 10^{4}, 5 \times 10^{4} \mathrm{e} 1 \times 10^{5}\right.$ zoósporos $\left./ \mathrm{mL}\right)$. No experimento 3 , o efeito da inoculação em diferentes idades das plântulas foi testado, inoculando-se plântulas dos três genótipos aos 45, 60, 75 e 90 dias após a semeadura, pelo método DSS com 5x $10^{4}$ zoósporos/mL. O tempo médio de sobrevivência (dias) das plantas após a inoculação foi avaliado e as médias comparadas pelo teste de Tukey (p>0,05). Assim, concluiu-se que o método DSS, as concentrações $5 \times 10^{4}$ ou $10^{5}$ zoósporos $/ \mathrm{mL}$ e plântulas com 60 dias de idade pós-semeadura podem ser utilizados na avaliação de resistência do mamoeiro a $P$. palmivora.
\end{abstract}

Palavras-chave: Carica papaya, Peronosporales, método de inoculação, podridão-do-pé e dos frutos.

\begin{abstract}
Evaluation of inoculation methods, inoculum concentrations and seedling age for Phytophthora palmivora inoculation on papaya

A set of three experiments were conducted in a completely randomized design with 10 replications/treatment aimed at evaluating inoculation methods, inoculum concentrations and seedling age to establish an effective methodology for evaluating papaya accesses for resistance to P. palmivora. In experiment 1, 60 days-old seedlings of three genotypes (Golden, Kapoho Solo and Calimosa) were inoculated using three methods - deposition of $1 \mathrm{~mL}$ of zoospore suspension around seedlings planted on wet (DSW) and dry substrate (DDS), and immersion of the seedling root system in $200 \mathrm{~mL}$ of the inoculum suspension for 20 minutes (IRS) - and five inoculum concentrations $5 \times 10^{3}, 10^{4}, 5 \times 10^{4}, 10^{5}$ and $5 \times 10^{5}$ zoospores $/ \mathrm{mL}$; in experiment two, two genotypes (Golden and Kapoho Solo), two inoculation methods (DSE and DSS) and three inoculum concentrations $\left(10^{4}, 5 \times 10^{4}\right.$ and $\left.10^{5}\right)$ were tested. Experiment three was aimed at selecting an adequate seedling age. Three papaya genotypes at ages of 45, 60, 75 and 90 days were inoculated through the DSS method using the inoculum concentration of $5 \times 10^{4}$ zoospores $/ \mathrm{mL}$ and 25 seedlings/treatment. In all experiments the mean number of days of seedling survival after inoculation (days) was utilized for treatment comparisons using Tukey's statistical test $(p>0,05)$. Results of the experiments have indicated that the DDS method of inoculation, the use of 60 day-old seedlings and application of a suspension of $10^{5}$ or $5 \times 10^{4}$ zoospores $/ \mathrm{mL}$ are adequate for accessing papaya seedling resistance against $P$. palmivora.
\end{abstract}

Key words: Carica papaya, Peronosporales, foot-and-fruit-rot, methodology of inoculation.

\section{INTRODUÇÃO}

O mamoeiro (Carica papaya L.), uma fruteira de grande importância para o agronegócio brasileiro, tem merecido destaque em função da alta produção e do alto nível tecnológico aplicado à cultura (Nakasone, 1994). O Brasil é um dos líderes na produção da fruta, sendo o estado da Bahia o maior produtor, com cerca de 42.000 ha de área cultivada e 1,6 milhão de toneladas produzidas por ano, sendo o estado do Espírito Santo o maior exportador
(IBGE, 2009). A fruta é usada como fonte importante de papaína, enzima proteolítica de ação semelhante a da pepsina e tripsina, empregada para os mais variados usos nas indústrias têxteis, farmacêutica, de alimentos e de cosméticos. Das folhas, dos frutos e das sementes do mamoeiro é extraído também um alcalóide denominado carpaína, utilizado como ativador cardíaco. Além disso, o mamão é boa fonte de cálcio e excelente fonte de pró-vitamina $\mathrm{A}$ e de ácido ascórbico (vitamina C), sendo que o teor deste último aumenta com a maturação do fruto (Trindade, 2000). 
Entre as principais doenças que limitam a produção deste fruto está a podridão-do-pé e dos frutos do mamoeiro, causada por Phytophthora palmivora (Butl.) Butl., a qual ocorre praticamente em todas as regiões produtoras da fruta no mundo (Silva, 2001). A doença foi primeiramente descrita no Brasil por Batista (1946) nos estados da Bahia e Pernambuco. Posteriormente, ela foi identificada em outros estados como Espírito Santo (Liberato et al., 1993) e Maranhão (Silva et al., 1999).

As condições favoráveis à infecção e ao desenvolvimento da doença são principalmente as altas temperaturas, elevada umidade relativa do ar e umidade do solo (Ko, 1971). O patógeno possui uma gama variada de hospedeiros, incluindo mais de 100 espécies de várias famílias botânicas e que possuem grande relevância econômica, como: cacau (Theobroma cacao) (Zehntner, 1914), coqueiro (Cocos nucifera) (Batista, 1946) e pimentado-reino (Piper nigrum) (Holliday, 1965), entre outros.

No Brasil, não há estatísticas precisas a respeito dos danos causados pela podridão-do-pé e dos frutos. Em plantios comerciais de mamão na Ilha de São Luís, Maranhão, em estação chuvosa, estimou-se que de $40 \%$ a $60 \%$ das plantas foram perdidas em diversas propriedades no ano de 1999 (Silva et al., 1999). Na Bahia, Tavares (2009), amostrou 34 pomares de mamoeiro de diversos municípios da região sul encontrando $P$. palmivora no solo de 32 deles.

A utilização de cultivares com algum nível de resistência é a forma mais econômica de controlar $P$. palmivora em mamoeiro (Dianese, 2006). No entanto, a literatura sobre o assunto é escassa e não se dispõe de um método de inoculação artificial eficiente e que se assemelhe à infecção natural. Os métodos mais citados na literatura são: imersão do sistema radicular em uma suspensão de zoósporos ou esporângios; derramamento de suspensão de zoósporos ou clamidósporos diretamente no substrato ao redor do colo da planta (Trujillo \& Hine, 1965; Silva, 2001); infestação do solo antes do plantio com suspensão de zoósporos ou clamidósporos (Ramirez \& Mitchell, 1975); utilização de solo naturalmente infestado (Dianese, 2006) e inoculação com suspensão de zoósporos após a saturação do solo com água (Tocafundo, 2008). A idade das plantas e a concentração de inóculo devem ser ajustadas ao método empregado. As concentrações mais utilizadas são $1 \times 10^{3}$ esporângios e $5 \times 10^{5}$ zoósporos $/ \mathrm{mL}$ (Kim et al., 1996; Trujillo \& Hine, 1965). Com o objetivo de estabelecer uma metodologia padrão para testar a resistência a podridãodo-pé do mamoeiro, foram avaliados três métodos de inoculação, cinco concentrações de inóculo e quatro idades das plântulas.

\section{MATERIAL E MÉTODOS}

Os experimentos foram desenvolvidos em casade-vegetação da Seção de Fitopatologia e no Laboratório de Phytophthora da CEPLAC no Centro de Pesquisas do Cacau (CEPEC) em Ilhéus BA, utilizando o isolado 356 de
P. palmivora da Coleção de Phytophthora Arnaldo Gomes Medeiros. Este isolado foi obtido originalmente de raízes de mamoeiro infectadas com a doença, no município de Mucuri BA. Para todos os experimentos foram realizados as seguintes etapas:

\section{Preparo do substrato, semeadura e manutenção das plântulas}

Sementes de mamoeiro dos genótipos Golden (suscetível), Kapoho Solo (moderadamente resistente) e Calimosa (resistente) foram semeadas em bandejas com 54 tubetes cada uma, com capacidade para $300 \mathrm{~cm}^{3}$, contendo como substrato Plantimax (50\%) + solo autoclavado (50\%). Foram plantadas 3 sementes/tubete a $1 \mathrm{~cm}$ de profundidade e após a germinação procedeu-se o desbaste deixando-se apenas uma plântula/tubete. As plântulas foram mantidas em bancadas com sistema misto de cobertura e a pleno sol. O sistema de irrigação por aspersão era ligado conforme as condições climáticas: nos dias de pleno sol, três vezes ao dia, com irrigação de 10 minutos e, nos dias chuvosos, era desligado. As plântulas foram fertirrigadas quinzenalmente, utilizando o bio-fertilizante Bioamino ${ }^{\circledR}$ (20 litros de água para $50 \mathrm{~mL}$ do produto).

\section{Preparo do inóculo}

O inóculo foi preparado por transferência de fragmentos de colônias obtidas da coleção para placas de Petri de $9 \mathrm{~cm}$ de diâmetro contendo cenoura-ágar (CA), que foram mantidas em câmara de crescimento (BOD) com temperatura de $25{ }^{\circ} \mathrm{C}$ e luz constante durante dez dias. Ao final deste período, $8 \mathrm{~mL}$ de água destilada, esterilizada e gelada foram adicionados a cada placa, e estas colocadas em geladeira por 20 minutos. Logo após, foram deixadas sob temperatura ambiente durante 25 minutos para liberação dos zoósporos. As suspensões obtidas em cada placa foram vertidas cuidadosamente em um béquer e a suspensão composta foi colocada na geladeira para evitar a germinação dos zoósporos, enquanto era aferida a concentração de zoósporos na suspensão em hemacitômetro. Posteriormente, a suspensão original foi utilizada para a preparação de suspensões ajustadas para $5 \times 10^{3}, 10^{4}, 5 \times 10^{4}, 10^{5}$ e $5 \times 10^{5}$ zoósporos $/ \mathrm{mL}$, procedendo-se imediatamente a inoculação das plântulas, conforme o tratamento que iriam receber.

\section{Experimento 1}

\section{Métodos de inoculação}

No experimento foram utilizados três métodos de inoculação.

\section{Método 01 - Deposição do inóculo no substrato encharcado (DSE)}

Os tubetes com as plântulas que estavam com aproximadamente $15 \mathrm{~cm}$ de altura (60 dias após a semeadura), foram imersos em água, ao nível da borda do tubete até atingir a saturação do substrato. Em seguida, 
procedeu-se a deposição de $1 \mathrm{~mL}$ da suspensão de zoósporos de $P$. palmivora em cada tubete, com o auxílio de uma pipeta automática, respeitando-se os tratamentos de acordo com as concentrações acima mencionadas. $\mathrm{O}$ procedimento foi realizado de forma cuidadosa, depositando-se o inóculo na superfície do substrato, sem atingir a plântula. Os tubetes permaneceram imersos por mais 1 hora e depois deste período, foram retirados lentamente da água e colocados em casa-de-vegetação climatizada.

\section{Método 02 - Deposição do inóculo no substrato sem encharcamento (DSS)}

As plântulas foram inoculadas também por deposição de $1 \mathrm{~mL}$ da suspensão de $P$. palmivora na concentração preconizada para o tratamento conforme descrito acima mas por deposição da suspensão diretamente sobre o substrato sem encharcamento. Ao aplicar a suspensão teve-se o cuidado de não atingir o coleto das plântulas. Estas permaneceram em casa-de-vegetação climatizada após a inoculação.

\section{Método 03 - Imersão do sistema radicular em suspensão de zoósporos (ISR)}

As plântulas foram retiradas dos tubetes com todo cuidado para não causar danos ao sistema radicular, que foi lavado em água corrente para remover os resíduos do substrato, e a seguir imerso por 20 minutos em $200 \mathrm{~mL}$ das suspensões de zoósporos. Após esse período, as plântulas foram cuidadosamente transplantadas para os tubetes contendo substrato Plantimax $(50 \%)+$ solo esterilizado $(50 \%)$.

No experimento 1 foi adotado um esquema fatorial $3 \times 3 \times 5$ (3 genótipos, 3 métodos e 5 concentrações de inóculo), em delineamento inteiramente casualizado com 10 repetições e 45 tratamentos. As mesmas metodologias foram aplicadas às testemunhas, sendo o inóculo substituído por água. $\mathrm{O}$ experimento foi repetido em duas épocas distintas.

\section{Experimento 2}

Neste experimento foram utilizados apenas dois métodos de inoculação: DSE e DSS, dois genótipos (Golden e Kapoho Solo) e as concentrações $10^{4}, 5 \times 10^{4}$ e $10^{5}$ zoósporos/ $\mathrm{mL}$. Como testemunha igual número de plantas receberam somente água. $\mathrm{O}$ experimento foi em esquema fatorial com delineamento inteiramente casualizado, 16 tratamentos e 25 repetições $(2 \times 2 \times 4)$. Avaliou-se o tempo médio de vida das plantas. $\mathrm{O}$ experimento foi repetido em duas épocas distintas.

\section{Experimento 3: Efeito da inoculação em plântulas de diferentes idades}

Para determinar o efeito da inoculação de $P$. palmivora em plântulas com diferentes idades esposta à inoculação com foram empregados os genótipos Golden, Kapoho Solo e Calimosa. As plântulas foram inoculadas com 45, 60, 75 e 90 dias após o plantio, utilizando a concentração de $5 \times 10^{4}$ zoósporos $/ \mathrm{mL}$ e o método DSS. O experimento foi em delineamento inteiramente casualizado, em arranjo bifatorial $3 \times 4$ ( 3 cultivares e 4 idades) com 30 repetições e as testemunhas. $\mathrm{O}$ experimento foi repetido em duas épocas distintas.

\section{Avaliação e análise dos dados.}

Em todos os experimentos as plântulas foram avaliadas diariamente após as inoculações para observação dos sintomas em cada tratamento, anotando-se o número de plântulas murchas e mortas para cálculo da variável tempo médio de vida (sobrevivência após a inoculação). Tão logo tombavam as plântulas eram levadas ao laboratório lavadas, desinfestadas superficialmente e plaqueadas em meio seletivo PARPH (Kannwischer \& Mitchell, 1978) para confirmação da presença de $P$. palmivora. Foi utilizado o programa computacional SAS para análise (ANOVA), sendo os tempos médios de vida das plântulas de cada tratamento comparados entre si pelo teste Tukey ao nível de $5 \%$ de significância.

\section{RESULTADOS}

A partir do quinto dia de inoculação, independente do método de inoculação utilizado, algumas plântulas apresentaram sintomas da doença, e, com aproximadamente dez dias, várias delas já estavam tombadas em decorrência da infecção pelo patógeno. Observou-se que, de um modo geral, a partir do $10^{\circ}$ dia após a inoculação, o número de plântulas que morriam era menor, principalmente na variedade Kapoho. Os períodos mais críticos para infecção foram os 10 primeiros dias após a inoculação. As plântulas apresentavam amarelecimento, seguido de anelamento na região do coleto, tombamento e morte. Quando tombadas, seus sistemas radiculares apresentavam-se completamente apodrecidos. O patógeno foi re-isolado de todas as plântulas tombadas.

O tempo máximo de vida após a inoculação foi 30 dias, pois a maioria das plântulas inoculadas, independente do método ou da concentração de inóculo, já havia apresentado sintomas da doença e/ou morrido. As testemunhas, para os três métodos de inoculação estavam vivas e sem apresentar sintomas à época do descarte do experimento. Detectaramse efeitos significativos de genótipos, métodos de inoculação e concentração de inóculo $(p>0,05)$ nos experimentos 1 e 2 , sem que ocorressem interações significativas entre as três. Tal fato indicou que os efeitos dessas variáveis foram independentes entre si (Tabela 1).

No experimento 1 as plântulas do genótipo Kapoho, tiveram um tempo médio de vida superior aos demais genótipos. No entanto, o genótipo Calimosa, considerado empiricamente como tolerante à podridão-do-pé e dos frutos do mamoeiro, não diferiu estatisticamente do genótipo Golden, comprovadamente suscetível. Este último genótipo, nos experimentos realizados, apresentou tempo médio de vida entre 15 (experimento 1) e 17 dias (experimento 2) após a inoculação com P. palmivora. 
TABELA 1 - Tempo médio de vida (sobrevivência em dias) das plântulas de três genótipos de mamoeiro após inoculação com Phytophthora palmivora por diferentes métodos de inoculação (DSE - deposição em substrato encharcado, DSS - deposição em substrato sem encharcamento, ISR - imersão do sistema radicular) e concentrações de inóculo

\begin{tabular}{|c|c|c|}
\hline \multirow[t]{2}{*}{ Fatores } & \multicolumn{2}{|c|}{ Experimentos } \\
\hline & 1 & 2 \\
\hline \multicolumn{3}{|l|}{ Genótipos (G) } \\
\hline Golden & $14,8 \mathrm{~b}$ & $16,9 \mathrm{~b}$ \\
\hline Kapoho Solo & $17,8 \mathrm{a}$ & $20,9 \mathrm{a}$ \\
\hline Calimosa & $16,1 \mathrm{~b}$ & - \\
\hline DMS & 1,68 & 1,90 \\
\hline \multicolumn{3}{|l|}{ Métodos de inoculação (M) } \\
\hline DSE & $18,6 \mathrm{a}$ & $20,3 \mathrm{a}$ \\
\hline DSS & $19,0 \mathrm{a}$ & $17,5 \mathrm{~b}$ \\
\hline ISR & $11,2 \mathrm{~b}$ & - \\
\hline DMS & 1,69 & 1,90 \\
\hline \multicolumn{3}{|l|}{ Concentração de inóculo } \\
\hline $5 \times 10^{3}$ zoósporos $/ \mathrm{mL}$ & $18,8 \mathrm{a}$ & - \\
\hline $10^{4}$ zoósporos $/ \mathrm{mL}$ & $18,2 \mathrm{a}$ & $21,0 \mathrm{a}$ \\
\hline $5 \times 10^{4}$ zoósporos $/ \mathrm{mL}$ & $15,4 \mathrm{~b}$ & $20,5 \mathrm{a}$ \\
\hline $10^{5}$ zoósporos $/ \mathrm{mL}$ & $14,4 \mathrm{~b}$ & $15,3 \mathrm{~b}$ \\
\hline $5 \times 10^{5}$ zoósporos $/ \mathrm{mL}$ & $14,2 \mathrm{~b}$ & - \\
\hline DMS & 2,53 & 2,79 \\
\hline Causa de variação & $\mathrm{p}>\mathrm{F}$ & $\mathrm{p}>\mathrm{F}$ \\
\hline Genótipo (G) & $<0,0001$ & 0,0002 \\
\hline Métodos de Inoculação (M) & $<0,0001$ & 0,0046 \\
\hline Concentração de Inoculo (C) & $<0,0001$ & $<0,0001$ \\
\hline Interação G x M & $0,5682^{\mathrm{NS}}$ & $0,2459^{\mathrm{NS}}$ \\
\hline Interação G x C & $0,9392^{\mathrm{NS}}$ & $0,0819^{\mathrm{NS}}$ \\
\hline Interação M x C & $0,1253^{\mathrm{NS}}$ & $0,7595^{\mathrm{NS}}$ \\
\hline Coeficiente de Variação (\%) & 23,69 & 18,26 \\
\hline
\end{tabular}

Ns_ não significativo $(\mathrm{p}>0,05)$, leitura feita aos 30 dias após a inoculação. Médias seguidas da mesma letra nas colunas não diferem entre si pelo teste de Tuckey (5\%)

Quanto aos métodos de inoculação, observou-se na análise do experimento 1 que as plantas tratadas por ISR foram as que apresentaram menor tempo de vida (11 dias), em relação aos demais métodos, que não diferiram entre si. No experimento 2 a utilização do método DSS resultou num tempo médio de vida (17,5 dias) significativamente menor do que o método DSE (Tabela 1).

Analisando-se os dados dos experimentos 1 e 2 em conjunto, a média de sobrevivência das plântulas foi de 18 dias para o método DSS, enquanto para o método DSE foi 19 dias. Para o experimento 1 os tempos médios de vida das plântulas inoculadas variaram de 10 (Genótipo Golden x ISR) a 21 dias (Genótipo Kapoho Solo x DSE). Para o experimento 2, a variação foi de 16 (Genótipo Golden x DSS) a 23 dias (Genótipo Kapoho Solo x DSE).
Plântulas inoculadas com todas as concentrações de zoósporos foram infectadas pelo patógeno. Os tempos médios de vida dessas plântulas, independente do genótipo ou do método de inoculação, variaram de 19 $\left(5 \times 10^{3}\right.$ zoósporos $\left./ \mathrm{mL}\right)$ a 14 dias $\left(5 \times 10^{5}\right.$ zoósporos $\left./ \mathrm{mL}\right)$ no experimento 1 . As concentrações mais altas $5 \times 10^{4}$, $1 \times 10^{5}$ e $5 \times 10^{5}$ zoósporos $/ \mathrm{mL}$, diferiram estatisticamente das mais baixas, $5 \times 10^{3}$ e $1 \times 10^{4}$ zoósporos $/ \mathrm{mL}$ (Tabela 1). Para este mesmo conjunto de dados os tempos médios de vida variaram de 12 (Genótipo Golden x concentração $10^{5}$ zoósporos) a 20 dias (genótipo Kapoho Solo x concentração de $5 \times 10^{3}$ zoósporos $/ \mathrm{mL}$ ).

No experimento 2, onde foram utilizadas apenas três concentrações, eliminando-se a mais alta e a mais baixa, o menor tempo médio de vida foi observado para as plântulas inoculadas com $10^{5}$ zoósporos/mL (15 dias). As duas outras concentrações $\left(1 \times 10^{4}\right.$ e $5 \times 10^{4}$ zoósporos $\left./ \mathrm{mL}\right)$ não diferiram entre si (Tabela 1). Para este experimento o tempo de vida das plantas variou de 12 dias (Genótipo Golden x concentração $10^{5}$ zoósporos $/ \mathrm{mL}$ ) a 22 dias (Genótipo Kapoho Solo x Concentração $10^{4}$ zoósporos $/ \mathrm{mL}$ ).

No experimento conduzido para verificação do efeito da inoculação em plantas de diferentes idades observou-se que em plântulas inoculadas já apresentavam sintomas a partir do quarto dia de inoculação, enquanto as testemunhas à época do descarte do experimento estavam sadias.

Através da análise dos dados observou-se que os valores de $\mathrm{F}$ foram significativos $(\mathrm{P}>0,05)$ para: genótipos, idade das plântulas e interação idade x genótipo (Tabela 2), não sendo significativo para o experimento, razão porque as duas repetições do experimento foram analisadas conjuntamente utilizando 60 plântulas por repetição, com o coeficiente de variação de 19,81\%. Como a interação genótipo $\mathrm{x}$ idade foi significativa, indicando que os efeitos de genótipos e idade da planta são dependentes, esta foi desdobrada e as médias comparadas pelo teste de Tukey ( $>00,05)$ (Tabela 3).

Plantas dos genótipos Golden e Kapoho Solo inoculadas aos 45 dias após a semeadura apresentaram tempos médios de vida estatisticamente iguais (12 dias), no entanto, as plântulas de Calimosa apresentaram uma sobrevida maior (16 dias) após a inoculação com $P$. palmivora (Tabela 3). Aos 60 e aos 90 dias após a semeadura

TABELA 2 - Resultados da ANOVA para a variável tempo médio de vida em dois experimentos com quatro idades de plântulas e três genótipos com 30 repetições cada

\begin{tabular}{ll}
\hline \hline Fonte de Variação & $\mathbf{p}>\mathbf{F}$ \\
\hline Experimento & $0,3449^{\mathrm{NS}}$ \\
Genótipo (G) & 0,0051 \\
Idade das Plantas (I) & $<0,0001$ \\
Interação G x I & 0,0095 \\
Coeficiente de Variação (\%) & 19,81
\end{tabular}

NS_ não significativo ( $\mathrm{p}>0,05)$, avaliação aos 60 dias após a inoculação. 
Avaliação de métodos, concentrações de inóculo e idade das plântulas para inoculação...

TABELA 3 - Probabilidade pelo teste de F e para a análise de variância com as variedades Golden, Calimosa e Kapoho Solo e teste de médias do tempo de vida (dias) dos genótipos inoculados (concentração de inóculo e método), de acordo com a idade das plântulas

\begin{tabular}{llccc}
\hline \hline \multirow{2}{*}{ Idade das Plântulas * } & \multicolumn{2}{c}{ Tempo médio de vida (dias) } & \multirow{2}{*}{$\mathbf{p}>\mathbf{F}$} \\
\cline { 2 - 3 } & Golden & Calimosa & Kapoho Solo & \\
\hline 45 dias & $11,9 \mathrm{~b} * *$ & $16,1 \mathrm{a}$ & $11,7 \mathrm{~b}$ & 0,0188 \\
60 dias & $16,2 \mathrm{~b}$ & $19,4 \mathrm{~b}$ & $21,3 \mathrm{a}$ & 0,0328 \\
75 dias & $29,9 \mathrm{a}$ & $26,8 \mathrm{a}$ & $35,3 \mathrm{a}$ & $0,0682^{\text {(NS) }}$ \\
90 dias & $31,4 \mathrm{~b}$ & $30,0 \mathrm{ab}$ & $39,4 \mathrm{a}$ & $0,320^{\text {(NS) }}$ \\
\hline
\end{tabular}

*Dias após a emergência /** Médias seguidas de mesma letra em linhas não diferem estatisticamente entre si pelo teste de Tuckey (5\%).

as plântulas do genótipo Kapoho Solo apresentaram maiores tempos de vida ( 21 e 39 dias respectivamente), em relação às plântulas de Golden (16 e 31 dias respectivamente), mas não diferiram significativamente daquelas do genótipo Calimosa aos 90 dias. Já aos 75 dias após a semeadura, não houve distinção entre genótipos quanto ao tempo médio de vida das plantas pós-inoculação (Tabela 3).

Analisando-se o efeito do tempo de vida dentro de cada genótipo, observa-se, que de modo geral, as plantas inoculadas aos 45 e 60 dias após a semeadura sobreviveram menos tempo à inoculação com P. palmivora do que aos 75 e 90 dias. Para os genótipos Golden e Calimosa não houve diferença significativa em relação ao tempo de vida quando inoculadas aos 60 dias, no entanto, para o genótipo Kapoho Solo a inoculação aos 45 dias reduziu significativamente o tempo de vida das plântulas (Tabela 3).

\section{DISCUSSÃO}

A inoculação de plântulas de mamoeiro pelos três métodos de inoculação confirmou que Phytophthora palmivora é um patógeno agressivo para esta espécie tanto para o genótipo considerado suscetível (Golden) quanto para o considerado resistente (Kapoho), causando a morte de plântulas independente da idade e da concentração de inóculo utilizada. Ao analisar os três métodos de inoculação, observou-se que as plântulas inoculadas através do método de imersão do sistema radicular apresentaram menores tempos médios de vida, o que já era esperado, por tratar-se de um método mais drástico, com exposição direta do sistema radicular ao patógeno. Além disso, mesmo retirando-se o sistema radicular do substrato com o máximo de cuidado, é inevitável que algum dano seja causado ao mesmo. Isso, certamente, facilitou ainda mais a entrada do patógeno, resultando na morte mais rápida das plântulas. Deste modo, este método não foi utilizado no experimento 2 , pois ele ainda apresentou três outras desvantagens que foram: a necessidade de um volume maior de inóculo (200 $\mathrm{mL}$ ), a demanda por mais espaço físico e o tempo mais longo tomado na sua execução, o que dificulta a inoculação de muitas plantas simultaneamente como é requerido em um experimento que visa selecionar genótipos resistentes.

O método DSE foi utilizado tentando simular as condições de campo, pois, a ocorrência de excesso de água nas plantações e altas precipitações pluviométricas favorecem epidemias da podridão-do-pé causada por $P$. palmivora $(\mathrm{Ko}, 1994)$. Sob estas condições, mesmo plântulas com mais de três meses de idade, que normalmente seriam resistentes $(K o, 1971)$ também podem ser atacadas. Sabe-se que, em áreas encharcadas ou mal drenadas a podridão pode ocorrer no sistema radicular de mamoeiros de qualquer idade. A necessidade de água no solo se deve ao fato de Phytophthora, como os demais Oomicetos, necessitar de água para esporulação e para movimentação dos zoósporos (Hunter \& Kunimoto, 1974; Luz \& Mitchell, 1994). Tocafundo (2008) utilizou este método (DSE) e verificou alta porcentagem de plântulas de mamoeiro Sunrise solo ou Golden mortas aos 5 dias após a inoculação, similar ao que foi encontrado nos experimentos aqui descritos. Tocafundo (2008) encontrou $100 \%$ de plantas mortas aos 7 dias. No entanto, os dados presentes demonstraram que os métodos DSE e DSS não diferiram estatisticamente (experimentos 1) e, no experimento 2 , as plântulas inoculadas pelo método DSS apresentaram menor tempo médio de vida (17,5 dias) (Tabela 1). Devido a praticidade de emprego, o método DSS deve ser selecionado para testes de resistência em cultivares ou genótipos de mamoeiro sob ambiente controlado.

Quanto à escolha da melhor concentração de inóculo, deve-se levar em consideração que para avaliar a resistência de genótipos de qualquer cultura a Phytophthora spp., não deve ser escolhida uma concentração que estabeleça um tempo médio de vida baixo ou um nível de infecção alto para as plantas, e nem tão pouco uma que proporcione tempo de vida muito elevado ou baixo nível de infecção (Luz \& Silva, 2001). Observando-se os dados na Tabela 1 e considerando que não houve interação entre genótipo e concentração de inóculo, não será possível estabelecer uma concentração padrão, pois todas as empregadas causaram infecção e morte de plântulas de mamoeiro inoculadas aos 60 dias de idade. No entanto, as concentrações $5 \times 10^{4} \mathrm{e}$ $10^{5}$ zoósporos $/ \mathrm{mL}$, que para o experimento 1 (Tabela 1) não diferiram entre si e também não diferiram de $5 \times 10^{5}$ zoósporos $/ \mathrm{mL}$, podem ser usadas para este fim. Segundo Ko (1971), plântulas com mais de 90 dias adquirem resistência em condições de campo a $P$. palmivora. Por esta razão não testamos idades superiores a 90 dias.

A inoculação de plantas mais jovens resultou em manifestação de sintomas mais precoces e mais intensos 
que a inoculação de plantas mais velhas, provavelmente em função da lignificação dos tecidos o que confere resistência natural à infecção pelo patógeno (Ko, 1994). Observou-se que com o aumento da idade da planta, ocorreu também um aumento significativo da resistência ao patógeno, refletido na média do tempo de vida em dias das plantas inoculadas (Tabela 3). Plântulas inoculadas aos 90 dias após a emergência, em todos os três genótipos testados, apresentaram maiores médias de tempo de vida.

Plântulas do genótipo Golden inoculadas aos $60 \mathrm{e}$ 90 dias após a semeadura sobreviveram menos tempo à inoculação do que as de Kapoho Solo (Tabela 3). De modo geral as plantas de Kapoho Solo apresentaram maiores tempos de vida dos que os outros dois genótipos utilizados, confirmando o que está enunciado na literatura consultada, onde Kapoho Solo é considerado resistente e Golden suscetível (Mosqueda-Vazquez et al., 1981; Oliveira \& Santos Filho, 2000). Aos 75 e aos 90 dias após a inoculação os valores de $\mathrm{F}$ não foram significativos (Tabela 3 ) e com aos 45 dias Kapoho Solo e Golden apresentaram tempos médios de vida estatisticamente iguais, a idade de 60 dias mostrou-se ideal proporcionando a perfeita distinção entre genótipos resistentes e suscetível.

Alguns autores citam a importância do fator idade das plantas nas inoculações para avaliação de resistência em outros patossistemas, como Citrus sp. x Phytophthora parasitica (Bowman \& Graham, 1996); Capsicum annuun $\mathrm{x}$ Phytophthora capsici (Reifschneider et al., 1986); Passiflora edulis f. flavicarpa x Phytophthora nicotianae var. nicotianae (Cole et al., 1992), como sendo um dos fatores que afetam a expressão da resistência dos genótipos ao patógeno. Mosqueda-Vazquez et al. (1981) mostram em pesquisas realizadas com mamoeiro, visando resistência genética à podridão-do-pé e dos frutos, que o fator idade das plantas influencia bastante no processo de patogênese, e que a idade das plantas ideal para se inocular $P$. palmivora é aos 60 dias após a semeadura. Os resultados apresentados no presente trabalho corroboram essas afirmações.

Assim, para inoculação de P. palmivora visando avaliação de resistência em mamoeiro é recomendável a utilização de DSS, inóculo com concentrações de $5 \times 10^{4}$ a $10^{5}$ zoósporos $/ \mathrm{mL}$ e usar plantas com 60 dias após a semeadura. A adoção deste padrão em futuras pesquisas com o patossistema mamoeiro x P. palmivora pode ser muito útil para a seleção de material genético resistente a este que é patógeno responsável por sérios danos à cultura do mamoeiro.

\section{AGRADECIMENTOS}

$\mathrm{O}$ primeiro e o segundo autores agradecem pela concessão de bolsas de mestrado e de produtividade em pesquisa respectivamente à Fundação de Amparo a Pesquisa do Estado da Bahia - FAPESB e ao Conselho Nacional de Desenvolvimento Científico e Tecnológico CNPq; externam também seu reconhecimento aos Drs. José
Luiz Bezerra, Enilton Santana Nascimento e Stela Dalva M. Silva pelas sugestões e contribuições a este trabalho, bem como ao matemático e estatístico Lindolfo Pereira dos Santos Filho, a doutoranda Ademilde de Oliveira Cerqueira, aos funcionários da Comissão Executiva do Plano da Lavoura Cacaueira - Ceplac pela inestimável colaboração. Agradecimentos são ainda devidos a Empresa Caliman Agrícola S/A pela cessão das sementes de mamoeiro.

\section{REFERÊNCIAS BIBLIOGRÁFICAS}

Batista AC (1946) Principais doenças das plantas no Nordeste. Boletim S.A.I.C., Recife. pp. 195-252.

Bowman KD, Graham JH (1996) In vitro evaluation of citrus rootstocks for resistance to Phytophthora nicotianae. Disponível em: http:// www.nal.usda.gov/ttic/tektran/data/00007/23/0000072 $353^{`} \mathrm{html}$.1996. Acesso em: 29 abril 2009.

Cole DL, Hedges R, Ndowora T (1992) A wilt of passion fruit (Passiflora edulis f. edulis Sims) caused by Fusarium solani and Phytophthora nicotianae. Tropical Pest Management 38:362-366.

Dianese A de C (2006) Variabilidade e controle de Phytophthora palmivora (Podridão-do-pé) e controle da varíola (Aperisporium caricae) do mamoeiro (Carica papaya). Tese de Doutorado. Brasília DF. Universidade de Brasília.

Kannwischer ME, Mitchell DJ (1978) The influence of a fungicide on the epidemiology of black shank of tobacco. Phytopathology 68:1760-1765.

Kim KD, Nemec S, Musson G (1996) Control of Phytophthora root and crown rot of bell pepper with composts and soil amendments in the greenhouse. Applied Soil Ecology 5:169-179.

Ko WH (1971) Biological control of seedling root rot of papaya caused by Phytophthora palmivora. Phytopathology 61:780-783.

Ko WH (1994) Phytophthora fuit rot and root rot In: Ploetz RC, Zentmyer GA, Nishijima WT, Rohrbach KG, Ohr HD (Eds.) Compendium of tropical fruit diseases. Saint Paul MN. APS Press. pp. 61-62.

Holliday PA (1965) A Wilt of Piper nigrum in Brazil. Commonwealth Phytopathology News 5:4.

Hunter JE, Kunimoto RK (1974) Dispersal of Phytophthora palmivora sporangia by wind-blown rain. Phytopathology 64:202206.

Instituto Brasileiro de Geografia E Estatística (2009) Produção agrícola municipal. Rio de Janeiro: IBGE. Disponível em http:// www.sidraibge.com.br Acesso em: 20 março 2009.

Liberato JR, Vanetti C, Rodrigues CH, Dias VP (1993) Ocorrência de Phytophthora em mamoeiro (Carica papaya L.) no Estado do Espírito Santo. Fitopatologia Brasileira 18:324.

Luz EDMN, Mitchell DJ (1994) Influence of soil flooding on cacao root infection by Phytophthora spp. Agrotrópica 2:53-60.

Luz EDMN, Silva SDVM (2001) Podridão-parda dos frutos, cancro e outras doenças causadas por Phytophthora no cacaueiro. In: Luz EDMN, Santos dos AF, Matsuoka K, Bezerra JL (Eds.) Doenças causadas por Phytophthora no Brasil. Campinas SP. Livraria e Editora Rural. pp. 175-265.

Mosqueda-Vazquez R, Aragaki M, Nakasone HY (1981) Screening 
of Carica papaya L. seedlings for resistence to root rot caused by Phytophthora palmivora Butl. Journal of the American Society for Horticultural Science 106:484-487.

Nakasone HY (1994) Papaya. In: Ploetz RC, Zentmyer GA, Nishijima WT, Rohrbach KG, Ohr HD (Eds.) Compendium of tropical fruit diseases. Saint Paul MN. APS Press. pp. 56-57.

Oliveira AAR, Santos Filho HP (2000) Doenças do mamoeiro. In: Ritzinger CHSP, Souza JS (Org.) Mamão Fitossanidade. Brasília: Embrapa Comunicação para Transferência de Tecnologia 11:3746.

Ramirez BN, Mitchell DJ (1975) Relationship of density of clamydospores and zoospores of Phytophthora palmivora in soil to infection of papaya. Phytopathology .65:780-785.

Reifschneider FJB, Café Filho AC, Rego AM (1986) Factors affecting expression of resistance in pepper (Capsicum annuun) to blight caused by Phytophthora capisici in screening trials. Plant Pathology35:451-456.

Silva GS, Urben AF, Doihara IP(1999) Ocorrência de Phytophthora palmivora em mamoeiro no estado do Maranhão. Fitopatologia Brasileira 24:S329.
Silva GS (2001) Podridão das raízes e dos frutos do mamoeiro. In: Luz EDMN, Santos AF, Matsuoka K, Bezerra LJ (Eds.) Doenças causadas por Phytophthora no Brasil. Campinas SP. Livraria e Editora Rural. pp. 413-432.

Tavares GM (2009) Podridão do pé do mamoeiro: infestação em solos de cultivo, controle alternativo com indutores de resistência e Trichoderma e avaliação dos mecanismos de defesa envolvidos. Tese de Doutorado. Recife, PE. Universidade Federal Rural de Pernambuco.

Trindade AV (2000) Mamão produção: aspectos técnicos. Cruz das Almas BA: EMBRAPA. Comunicação para Transferência de Tecnologia.

Tocafundo F (2008) Avaliação de isolados de Trichoderma spp. no controle de Phytophthora palmivora em mamoeiro. Dissertação de Mestrado. Ilhéus BA. Universidade Estadual de Santa Cruz.

Trujillo EE, Hine RB (1965) The role of papaya residues in papaya root rot caused by Pythium aphanidermatum and Phytophthora parasitica. Phytopathology 55:1293-1298.

Zehntner L (1914) Le cacaoyer dans L' Etat de Bahia. Berlim. Verlag R. Friedländer \& Sohn.

TPP 10018 - Recebido 20 Dezembro 2010 - Aceito 30 Novembro 2011 Editor de Seção: Francisco F. Laranjeira 